\title{
Distance Estimation in Reproduction Tasks in a Harbor Seal (Phoca vitulina)
}

\author{
Eric Maaß and Frederike D. Hanke *(D)
}

check for

updates

Citation: Maaß, E.; Hanke, F.D Distance Estimation in Reproduction Tasks in a Harbor Seal (Phoca vitulina). Water 2021, 13, 938. https://doi.org/ $10.3390 /$ w13070938

Academic Editor: Nathan F. Putman

Received: 20 February 2021

Accepted: 24 March 2021

Published: 30 March 2021

Publisher's Note: MDPI stays neutral with regard to jurisdictional claims in published maps and institutional affiliations.

Copyright: (C) 2021 by the authors Licensee MDPI, Basel, Switzerland. This article is an open access article distributed under the terms and conditions of the Creative Commons Attribution (CC BY) license (https:// creativecommons.org/licenses/by/ $4.0 /$ )
Institute for Biosciences, Neuroethology, University of Rostock, Albert-Einstein-Str.3, 18059 Rostock, Germany; eric.maass@uni-rostock.de

* Correspondence: frederike.hanke@uni-rostock.de; Tel.: +49-381-666971914

Abstract: Harbor seals commute between haul-out places and feeding grounds close to the shore or in the open ocean, which is considered a low structured environment, at first sight not providing many cues for orientation/navigation. Nevertheless, seals are well-oriented. For returning to a specific location, seals may use both external and internal cues to, for example, perform path integration requiring the integration of distances traveled and angles steered. We herein assessed the seal's ability to estimate distances, previously swum or unknown, in reproduction tasks. Reproduction tasks refer to an experimental paradigm in which the experimental animal is required to swim a specific distance first and subsequently reproduce this distance, with visual cues present or absent. The seal was able to estimate and then reproduce distances $(0.5-18.5 \mathrm{~m})$ with the smallest error below $10 \%$ of the actual distance, and its precision was higher with distances repeatedly swum compared to its performance with unfamiliar distances. In the absence of visual cues, the seal's performance slightly dropped; however, it was still able to perform the task with an error of $21 \%$. In conclusion, distance estimation may help seals to navigate precisely towards their goals, even if, for example, visual information is not available.

Keywords: pinnipeds; navigation; spatial orientation; distance estimation; distance reproduction

\section{Introduction}

The open ocean, in contrast to the coastline or continental shelves, is considered a low-structured habitat. Nevertheless, marine mammals, such as cetaceans and pinnipeds, often travel through the open ocean searching for places where they can forage, rest or reproduce [1-4]. Some marine mammals even return to specific haul-out or birthplaces consistently. Moreover, on their journeys, some species are even able to steer straight courses. Research on humpback whales has revealed the animals' ability to keep a constant course with an accuracy of less than one degree over hundreds of kilometers traveled over many days [1]. Furthermore, pinnipeds, such as elephant seals, can keep a straight course even when submerged, most likely based on visual information obtained at the water surface; the envisaged direction is even maintained after a spiraling descend [5]. Thus, there is evidence that marine mammals are well oriented in their natural environment.

Seeing how well these animals are navigating, the question emerged which sensory information the seals and other marine mammals use for orientation and navigation. Theoretical speculation sprouted over the use of stars or the Earth's magnetic field [6-8]; while the first is based on good preliminary experimental evidence $[9,10]$, magnetoreception has not been documented for seals [11]. In general, previous experiments regarding orientation and navigation in seals almost exclusively focused on cues perceived by the classic sensory systems, such as visual, auditory, chemoreceptive or hydrodynamic cues [12-14]. However, in the marine environment, these cues can be impaired or absent due to environmental factors, such as turbidity [15], bad weather conditions or anthropogenic activities. Under these conditions, a seal could rely on navigation/orientation mechanisms that can be solely based on idiothetic cues, defined as cues derived from 
self-motion, such as path integration [16-18]. Fundamental to path integration is keeping track of distances covered, and directions steered on the outbound path. This information is then integrated into a homing vector, which leads the organism back to its starting point, for example, its haul-out place. The ability to integrate paths has already been shown in many terrestrial and some semi-terrestrial species [17,19-25]. We consider path integration to be a navigation mechanism very promising to look at in marine mammals in line with Fuiman et al. [26].

In this study, we analyzed if a harbor seal (Phoca vitulina) can estimate and reproduce distances in distance reproduction tasks. In a reproduction task, the experimental animal needs to swim a specific, predetermined distance. Afterwards, the animal must continue swimming until it subjectively decides it has reproduced this distance, meaning it has swum the distance another time. The estimation of distances is interesting regarding path integration, but it might also play a role in path return or might generally assist navigation in seals. Distance information can be derived from self-motion cues or cues derived from the classic sensory systems, most notably the visual system [18,27]. Most of our knowledge on distance estimation stems from human subjects. These experiments were often analyzing the influence of the visual system on distance estimation. In these experiments on nonvisual distance estimation and reproduction, researchers documented a high accuracy of reproduction with an absolute error of $20-35 \%$ of the path length [27] or slightly better. While the subjects veered noticeably, the distances were accurately reproduced. Thus, distance estimation is possible in the absence of vision. In Klatzky et al. [27], the mechanism used by the blindfolded subjects was not determined. However, since then, experiments, including normal and labyrinthine-defective human subjects, have shown that locomotor information and especially the vestibular system, can play a major role during distance estimation [28-30].

Possible mechanisms for distance estimation were also investigated in various animals. Honeybees rely on optic flow [31-35], whereas desert ants gauge distances additionally through a pedometer [36-39]. In mammals other than humans, experiments on distance estimation itself are scarce and, to our knowledge, have only been addressed in rodents, for example, in hamsters in a homing task on the basis of non-visual cues [18,40].

In the study at hand, we investigated distance estimation in a (semi)aquatic animal, the harbor seal. The distance reproduction task (experiment 1 ) involved a preset distance interval of $0.5-18.5 \mathrm{~m}$ length, which the subject had to reproduce subsequently by keeping the same swimming direction. A follow-up experiment (experiment 2) focused on the maximum precision the seal can achieve during a distance reproduction task. Finally (experiment 3 ), the influence of the visual system on distance reproduction was determined by comparing the seal's performance with and without a blindfold. We discuss our findings in the context of orientation/navigation of seals.

\section{Materials and Methods}

\subsection{Experimental Animal}

The experiment was conducted with an adult male, captive-born harbor seal (Phoca vitulina) named "Nick" (16 years old at the beginning of the experiments) at the Marine Science Center of the University of Rostock in Warnemünde/Hohe Düne, Germany. The seal had previously participated in many scientific experiments (see, for example, [12,41,42]). Nick was housed with eight other harbor seals, two juvenile California sea lions (Zalophus californianus), and an adult South African fur seal (Arctocephalus pusillus pusillus) in a seawater enclosure. The seal was mainly fed freshly thawed cut herring (Clupea harengus) and sprats (Sprattus sprattus). During the experiment and the general training, the animal received $1-5 \mathrm{~kg}$ of fish a day, depending on season and motivation. We performed experiments five days a week. 


\subsection{General Experimental Setup}

The experimental setup consisted of a belt-system stretched over $43 \mathrm{~m}$ (Figure 1). This was the maximum distance that could be covered within the largest enclosure of the Marine Science Center. The belt was painted in intervals of $10 \mathrm{~cm}$ using water-resistant paint to be able to use the belt as measuring tape. Although the belt was clamped, the units on the belt and on a calibrated measurement tape only deviated by $\pm 1 \%$.

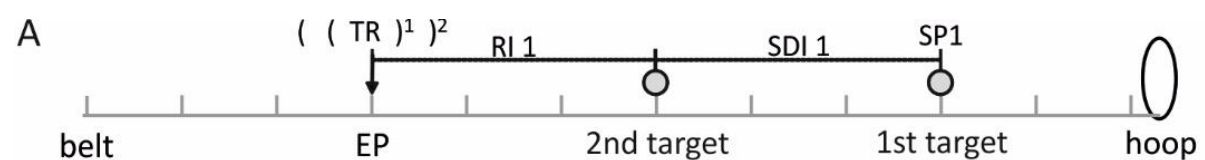

B

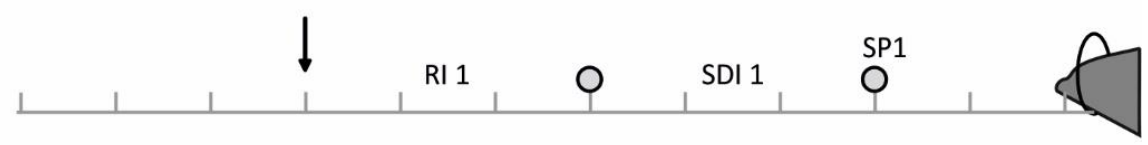

C

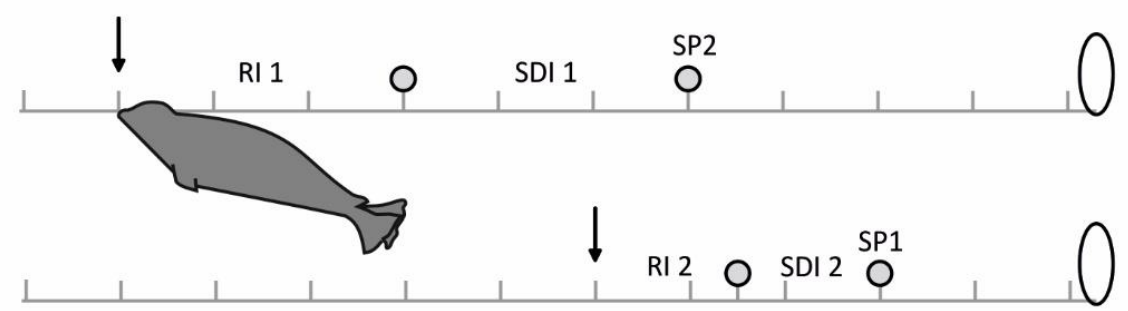

$\mathrm{E}$
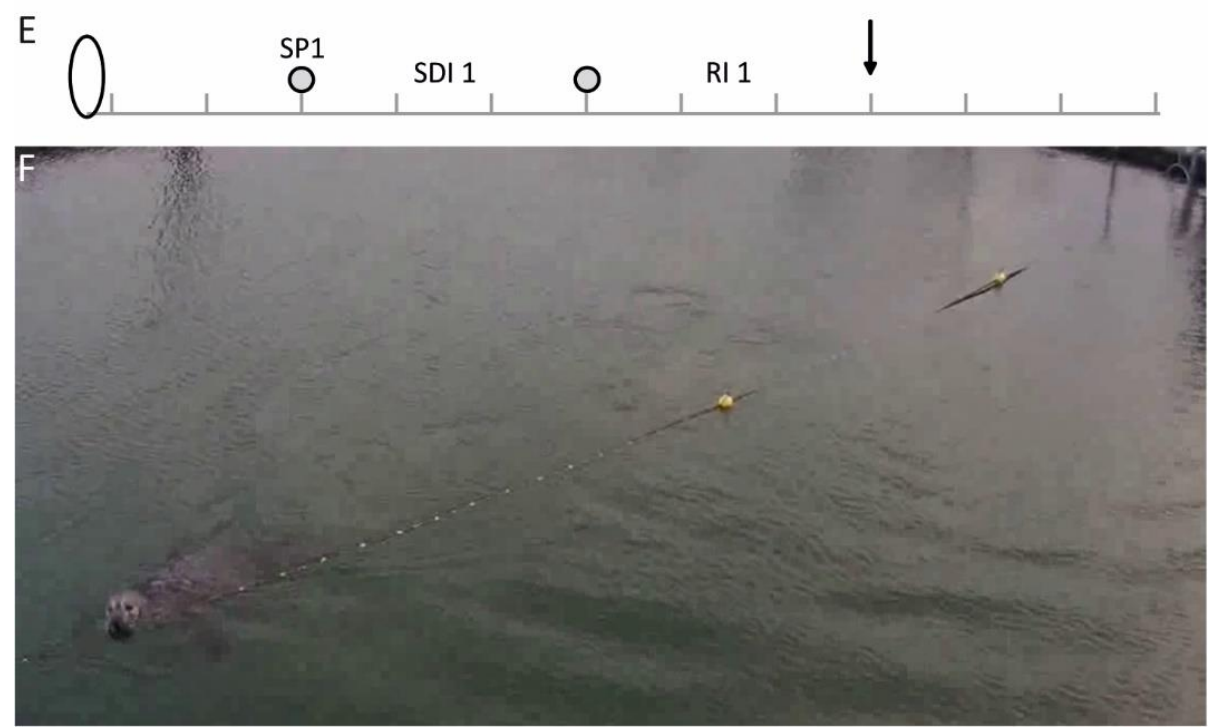

Figure 1. Experimental setup and procedure. (A) The basic components of the setup along a belt system are displayed, including a hoop station, in which the seal rested in between trials and two target-balls, the starting point (SP), the standard distance interval (SDI), and the reproduction interval (RI). For differential rewarding, we introduced two tolerance ranges, TR1 and TR2 (see text for explanation). (B) The seal started every trial from its hoop station and passed two target-balls, marking the SDI along the belt system. It then had to reproduce the distance presented in the SDI in the RI. The seal was indicating the end of the RI by stationing at the belt; this point is defined as the seal's endpoint (EP; black arrow). (B,C) Throughout the experiment, the SP was varied along the belt and/or (D) the distance within the SDI was varied. (E) After the testing phases in stages 1 to 4 of experiment 1 , we conducted a control session in which the animal had to perform the task in the opposite swimming direction. (F) Image of the camera recording the experimental trials. The seal has passed the two target balls, has reproduced the distance presented in the SDI (here: a $3 \mathrm{~m}$ distance was presented) and now indicates its decision by resting at the belt. 
Two balls were clipped onto the belt that served as the starting point (SP) and endpoint (EP) of the sample distance interval (SDI, see Figure 1). The SP was defined as the distance from the hoop station, in which the seal was resting during the inter-trial interval, to the first target ball. The second target ball also indicated the start of the reproduction interval (RI). Both target balls could be shifted in position along the belt (Figure 1) according to a preset schedule (Table 1). This way, the SDI could be presented at different positions in space defined by the SP. The variation of the position of the SDI and RI along the belt achieved by the variation of the SPs served to minimize the possibility that the seal was learning EPs defined absolutely in space to solve the task instead of estimating/reproducing the distance in the SDI. For the control session, the belt system was clamped from the other side of the enclosure (Figure 1E).

Table 1. Overview of the pretraining $(\mathrm{P})$ and the experimental stages $1-5$ of experiment 1 . Indicated are the distances presented in the standard distance interval (SDIs in $\mathrm{m}$ ) from the respective starting points (SPs in $\mathrm{m}$ from the hoop station) and the number of trials conducted during the acquisition phase and during the testing phase, as well as the respective tolerance ranges (TR1 and TR2) for the different distances.

\begin{tabular}{|c|c|c|c|c|c|c|c|}
\hline \multirow[b]{2}{*}{ Stage } & \multirow[b]{2}{*}{ SDI (m) } & \multicolumn{2}{|c|}{ Tolerance Range } & \multicolumn{2}{|c|}{ Acquisition Phase } & \multicolumn{2}{|c|}{ Testing Phase } \\
\hline & & TR1 (m) & TR2 (m) & $\mathrm{SP}(\mathrm{m})$ & Number of Trials & $\mathrm{SP}(\mathrm{m})$ & Number of Trials \\
\hline $\mathrm{P}$ & 5 & \pm 0.5 & \pm 1 & 1 & 280 & & \\
\hline \multirow[t]{2}{*}{1} & 10 & \pm 0.5 & \pm 1 & 3 & $516^{1}$ & & \\
\hline & 5 & \pm 0.5 & \pm 1 & 3,6 & 444 & $4,6,8,10,12,14$ & 150 \\
\hline \multirow{3}{*}{2} & 3 & \pm 0.3 & \pm 1.0 & & 859 & \multirow{3}{*}{$4,6,8,10,12,14$} & \multirow{3}{*}{300} \\
\hline & 7 & \pm 0.7 & \pm 1.5 & $2,4,8$ & 864 & & \\
\hline & $(12)^{2}$ & \pm 1.2 & \pm 2.4 & & 177 & & \\
\hline \multirow{2}{*}{3} & 1 & \pm 0.1 & \pm 0.2 & \multirow{2}{*}{$2,4,8$} & \multirow{2}{*}{643} & \multirow{2}{*}{$4,6,8,10,12,14$} & \multirow{2}{*}{300} \\
\hline & 11 & \pm 1.1 & \pm 2.2 & & & & \\
\hline 4 & $1,3,7,11$ & see above ${ }^{3}$ & see above ${ }^{3}$ & $2,4,8$ & 1646 & $4,6,8,10,12,14$ & 600 \\
\hline 5 & various ${ }^{4}$ & $\pm 10 \%$ & $\pm 20 \%$ & & & various $^{4}$ & 29 \\
\hline
\end{tabular}

${ }^{1}$ In stage 1 , the seal started with an SDI of $10 \mathrm{~m}$, which the seal, however, did not learn to reproduce in 516 trials. Thus, the SDI was changed to $5 \mathrm{~m} .{ }^{2}$ Stage 2 was initially started with three SDIs. The seal did not reach the learning criterion in 531 trials with the $12 \mathrm{~m}$ distance included. Thus, we excluded the $12 \mathrm{~m}$ distance and proceeded with only two distances, $3 \mathrm{~m}$ and $7 \mathrm{~m} .^{3}$ The tolerance ranges for the SDIs of stage 4 were chosen as during the previous experimental stages, in which the respective SDI had already been tested. ${ }^{4}$ In stage 5 , 29 different SPs and distances were presented to the animal. Each combination occurred only once (see Appendix A).

\subsection{General Experimental Procedure}

Each trial began with the experimenter asking the animal to station in the hoop station (Figure 1). Then the experimenter positioned the target balls and thus laid out the SP/SDI combination of the respective trial with the help of an observer. The observer was situated at an elevated position, from which she/he could oversee the whole experiment.

On verbal command by the experimenter, the seal left the hoop station and started to move alongside the belt to the SP. The seal then proceeded to the second target ball at the end of the SDI. It was then required to reproduce the distance presented in the SDI by swimming further along the belt. A trial ended when the seal stationed at the belt.

The accuracy of reproduction was determined by the observer and was communicated to the experimenter, who could then reward the animal according to its performance. When reading the belt during the experiment, the error of the observer was determined as $\pm 2 \%$. Exact reproduction, meaning that SDI and RI were equal in distance, led to a reward of five pieces of fish. For the purpose of differential rewarding, we introduced two tolerance ranges (TRs; Table 1). Reproduction within the predefined first tolerance range (TR1) led to a reward of three pieces of fish. If the animal reproduced the distance within the predefined second tolerance range (TR2), it received a reward of one piece of fish. In stage 1, the TR1 was set to $1 \mathrm{~m}$, approximately half the body length of the animal, and the TR2 was $10 \%$ of the distance $(50 \mathrm{~cm})$. In the following experimental stages (stage $2-5)$, we chose relative percentile TRs (Table 1). The values we picked for both TRs were set in line with 
values from the literature $[27,43]$. No reward was given if the seal stopped outside the respective TRs.

The observer filmed the trials with a camera (Rollei Actioncamera 7S Wi-Fi, Hamburg, Germany) for further offline analysis of the animal's movements and behavior.

\subsection{Experiment 1}

Experiment 1 was divided into five experimental stages. Stages $1-4$ of the experiment were subdivided into a phase of acquisition, in which the seal was familiarized with (a) distance(s), a phase of testing, in which the precision of the seal was determined with familiar and unfamiliar SPs, and a control session, in which the experimental procedure was performed in reversed swimming direction. Stage 5 consisted of a phase of testing only.

In the acquisition phase, the seal had to reproduce the distance(s) from various preset SPs. The sessions were composed of 24-36 trials in which we presented distance/SP combinations following a pseudorandom schedule [44].

The acquisition phase was considered to be finished once the animal achieved the learning criterion. To reach the learning criterion, the seal's average precision of reproduction had to fall within TR1 (criterion 1). In addition, the standard deviation had to be smaller than $1 \mathrm{~m}$ (criterion 2). These criteria need to be met in two consecutive sessions for the acquisition phase to be completed and for the phase of testing to begin. When the seal had reached the learning criterion, its average precision of reproduction during the session was determined.

During the testing phase, the number of SPs was increased, further avoiding that the animal relied its responses on memorized absolute EPs. The general experimental procedure remained as in the acquisition phase. Each session consisted of 18 to 36 trials, and each distance was tested 25 times from each SP, totaling up to 150 trials per distance.

After each testing phase, except for phase 5, a control session was run. During this control session, the seal performed the experiment from the opposite side of the enclosure. Thus, the animal was in a familiar environment but experienced a new setting/panorama that it had never reproduced the distances from and consequently could not have gathered experience with in the first trial. In the control session, the distance(s) presented and the SPs, as well as the general experimental procedure, were the same as in the respective testing phase (Table 1).

\subsubsection{Pretraining}

During pretraining (P; Table 1), the seal was familiarized with the reproduction task. It was taught to swim towards the target balls with a $5 \mathrm{~m}$ distance presented in the SDI. After passing the second target ball, it had to proceed to a third target ball positioned $5 \mathrm{~m}$ away from the second target ball, marking the end of the RI. In one session, 10-23 trials were run. After a total of 280 trials, in which the seal learned this procedure, the third target ball was removed, and stage 1 could be started.

\subsubsection{Stage 1}

The acquisition phase of stage 1 was started with a $10 \mathrm{~m}$ distance presented from an SP at $3 \mathrm{~m}$ (Table 1). In each session, 30 trials were conducted. The TR1 was chosen as $\pm 0.5 \mathrm{~m}$. In addition, the TR2 was set at $\pm 1 \mathrm{~m}$ from the exact distance of $10 \mathrm{~m}$. In the acquisition phase, the seal did not show any signs of learning for the $10 \mathrm{~m}$ distance. We then chose to switch to the $5 \mathrm{~m}$ distance the animal had experienced during pretraining in an attempt to facilitate learning; the TRs remained as described. With this distance, we could complete the acquisition phase.

In each session during the testing phase, the seal was asked to reproduce the $5 \mathrm{~m}$ distance from six SPs, out of which the seal had only experienced the $3 \mathrm{~m}$-SP previously (Table 1).

Additionally, the seal was asked to reproduce the $5 \mathrm{~m}$ distance from these six SPs, however, with reversed swimming direction in a control session consisting of 30 trials. 


\subsubsection{Stage 2}

To test whether the seal could discriminate between distances, the distances $3 \mathrm{~m}, 7 \mathrm{~m}$, and $12 \mathrm{~m}$ were presented during stage 2 of experiment 1 . During the acquisition phase of stage 2, the distances were presented from three different SPs (Table 1). The TR1 was set at $\pm 10 \%$ of the distance; the TR 2 was defined as $\pm 1 \mathrm{~m}$ for the $3 \mathrm{~m}$ distance, $\pm 1.5 \mathrm{~m}$ for the $7 \mathrm{~m}$ distance and $\pm 2.4 \mathrm{~m}$ for the $12 \mathrm{~m}$ distance. In the acquisition phase, the seal easily learned to reproduce the $3 \mathrm{~m}$ and $7 \mathrm{~m}$ distance but had difficulties in learning to reproduce the $12 \mathrm{~m}$ distance. Consequently, we excluded the $12 \mathrm{~m}$ distance enabling us to proceed with training.

Once the learning criterion (see stage 1) was fulfilled, the number of SPs was increased to six SPs for the testing phase; four of these SPs were new to the seal.

\subsubsection{Stage 3}

In the third stage, the question was addressed whether the seal was capable of estimating and reproducing particularly small and long distances. Therefore, the distances of $1 \mathrm{~m}$ and $11 \mathrm{~m}$ were chosen (Table 1 ). The TRs in this session were set to $\pm 10 \%$ and $\pm 20 \%$ of the respective distance. SPs, learning criteria, and testing procedure were the same as in the previous stages.

\subsubsection{Stage 4}

In stage 4 , the seal's ability to reproduce four of the distances $(1 \mathrm{~m}, 3 \mathrm{~m}, 7 \mathrm{~m}, 11 \mathrm{~m})$ presented in stages 2 and 3 within one session was assessed. Together with three SPs, 12 different distance/SP-combinations were trained in the acquisition phase. Each combination was tested twice in a session of 24 trials until reaching the learning criterion. During the testing phase, the distances needed to be reproduced from four new and two old SPs as in the previous phases. The TRs in this session were set as in stage 3. Each distance/SP combination was tested once in 24 trials-sessions.

\subsubsection{Stage 5}

In stage 5 of the experiment, the seal was confronted with one session, in which a new distance was presented in every trial. Moreover, these unknown distances were presented from unknown SPs. Altogether 29 unfamiliar combinations of distances and SPs (see Appendix A) were tested. Here, TRs were set as in stage 3 (Table 1).

\subsubsection{Data Analysis}

To assess the precision of the animal during the session, we analyzed medium averages of signed and absolute error with Excel 2016 (Microsoft Corporation, Redmond, Washington WA, USA) in line with the analysis of Bigel and Ellard [45]. Additionally, we used IBM SPSS (v.26; International Business Machines Corporation Armonk, New York, NY, USA) for the analysis of variances.

Saliences in the performance in both swimming directions were also studied. In a first-trial-analysis, we compared the performance during the first trials during the control session swum for each distance and SP in reversed swimming direction with the average performance of the animal in the testing phase. This analysis was informative regarding the influence of memorized EPs on the performance in the previous stages of the experiment. The learning of EPs could have influenced the performance of the animal during the testing and acquisition phases, although we drastically reduced this possibility by varying the intervals along the belt, but could not influence its performance in the first trial in reversed swimming direction, as the animal had no previous memory of the EP.

All videos made during data collection by the observer were analyzed with Avidemux (v.2.6; http:/ / fixounet.free.fr/avidemux/ (accessed on 15 May 2017)). We analyzed the swimming speed in the RI by calculating the time elapsing between the animal leaving the second target ball and the animal stopping at the belt at its chosen EP. Since it was not 
always unambiguous at which frame the seal touched the second target ball or stopped at the belt, we calculated the resulting error in swimming speed, which amounted to $\pm 2 \%$.

In stage 4, with four distances presented, we investigated if the seal used specific motion patterns for reproducing a specific distance. We chose to investigate the movement patterns in stage 4 only since this was the sole stage in which the animal experienced more than two distances over a longer period. After reviewing the videos, we could classify the movements of the seals in every single trial and analyzed how often a specific movement pattern occurred during the reproduction of a specific distance. We performed a $\mathrm{Chi}^{2}$ test to test if the seal performed better if it moved with a specific motion pattern.

The ethogram consisted of the following movement patterns:

1. "touch-dive-drift" - the animal casually strived the second target ball, performed a flap with its fin and began diving. After diving, the seal surfaced, drifted, and then stopped;

2. "touch-dive-stop"- the animal quickly touched the second target ball with full snout contact and started a dive. After resurfacing, it immediately stopped;

3. "touch-drift"-the animal touched the second target ball with full snout contact and started gliding. During gliding, it performed a turn until it stopped;

4. "touch-stop"-after touching the second target ball, the seal swam continuously at the water surface until stopping entirely;

5. "other"- the seal showed a movement pattern different from points 1-4.

\subsection{Experiment 2}

In experiment 1, predefined TRs mostly adapted from the literature were used to train the animal. In experiment 2, we wanted to test the precision of reproduction the seal can maximally achieve. Therefore, the seal was trained to reproduce a new distance, which was kept constant during the experiment. It was presented from 24 SPs in a 24 trials-session; these 24 SPs were used throughout experiment 2 in randomized order.

Training started with a preset TR. After reaching the learning criterion, defined as a performance with an absolute error of $\leq 20 \%$ achieved in two consecutive sessions, the TR was reduced by $2.5 \%$ (9 m distance) or $5 \%$ ( $2 \mathrm{~m}$ and $13 \mathrm{~m}$ distance). This way, the TR was continuously reduced until the seal was unable to reach the learning criterion within 5-10 sessions. We finally decided to run only five sessions as the seal's performance did not increase over ten sessions; thus, no learning seemed to have taken place neither over five sessions nor over ten sessions. The maximum precision of reproduction was determined for three distances in the following order: $9 \mathrm{~m}, 2 \mathrm{~m}$, and $13 \mathrm{~m}$.

We used IBM SPSS for the statistical analysis of the data.

\subsection{Experiment 3}

In experiment 3 , the influence of the visual system on the performance of the animal was determined. Hereby, the general procedure was as in the previous experiments. However, now every session included baseline and masked trials. In the baseline trials, the seal was presented with a $4 \mathrm{~m}$ distance, which had never been presented to the animal before, from four different SPs: $3 \mathrm{~m}, 4 \mathrm{~m}, 5 \mathrm{~m}$, and $6 \mathrm{~m}$. In each session, the distance was presented six times from each SP. Thus, a session included 24 baseline trials.

Within all sessions, masked trials were interspersed in which the seal had to complete the task with a blindfold, a latex mask over its eyes. The animal was highly experienced wearing masks and thus easily adapted to perform the task with a blindfold. With the interspersed masked trials, we could evaluate and compare the precision of reproduction in the baseline trials, in which the seal could rely on all available cues, and the masked trials, in which vision was occluded.

At the beginning of training for experiment 3, the number of masked trials was increased within three sessions from four to the maximum number of eight masked trials within a session. Training continued until the learning criterion was met. The learning criterion was defined as the seal reproducing all baseline trials with an absolute error of 
$\leq 20 \%$ in two consecutive sessions. Thereafter, testing started in which the number of SPs was increased to six: $2 \mathrm{~m}, 3 \mathrm{~m}, 4 \mathrm{~m}, 5 \mathrm{~m}, 7 \mathrm{~m}$, and $8 \mathrm{~m}$. During testing, seven sessions were conducted with 18-24 trials. This cumulated in a total of 162 trials, including 108 baseline trials and 54 masked trials.

The performance of the animal was analyzed as in the previous experiment with IBM SPSS. Additionally, we also compared masked and unmasked trials in terms of precision of reproduction.

\section{Results}

\subsection{Experiment 1}

\subsubsection{Pretraining}

The seal had no difficulties in learning the basic experimental procedure. The familiarization with the experimental setup and procedure, meaning that the animal left the hoop station on command, proceeded to the first and second target-ball and finally stopped alongside the belt, took 280 trials (Table 1 ).

\subsubsection{Stage 1}

In stage 1 of experiment 1 , during the reproduction of a $10 \mathrm{~m}$ distance from an SP of $3 \mathrm{~m}$, the seal did not reach the learning criterion within 571 trials (Table 1). Thus, a new distance, $5 \mathrm{~m}$, from the $3 \mathrm{~m} \mathrm{SP}$ was presented to the seal. After 554 trials of training with this combination, the number of SPs was increased to two. After an additional 60 trials with these two SPs, the seal completed the acquisition phase by reaching the learning criterion (Table 1).

During the testing phase, the seal reproduced the $5 \mathrm{~m}$ distance with an overall absolute error of $13.3 \%(n=150)$. The overall signed error was $-7 \%$, indicating that the seal tended to undershoot the distance. We found a highly significant effect of the SPs on the accuracy of the seal's reproduction (Kruskal-Wallis test, $p<0.001$ ). Hereby, the seal overshot the $5 \mathrm{~m}$ distance by $+10.1 \%$ for the SP closest to the hoop station $(4 \mathrm{~m})$ and undershot the distances for all other SPs by $-2.6 \%$ to $-15.6 \%$ (Table 2 ).

Table 2. Overview of the absolute error (AE), the signed error (SE), and the performance in the first trial in opposite swimming direction in the control session (C). Described are medium averages (\%) per SP [in $\mathrm{m}$ from hoop station]. Each distance for each SP was tested 25 times. The algebraic signs indicated an overshooting $(+)$ or an undershooting $(-)$ of the respective distance. The final column shows the reproduction of every first trial with each distance in the control session (C). Numbers written in italics indicate the first trials of the control session within which the reproduction was outside of both TRs.

\begin{tabular}{|c|c|c|c|c|c|c|c|c|c|c|c|c|c|c|c|c|c|c|c|}
\hline \multirow{3}{*}{ Stage } & \multirow{3}{*}{$\begin{array}{l}\text { Distance } \\
\text { (m) }\end{array}$} & \multicolumn{18}{|c|}{$\mathrm{SP}(\mathrm{m})$} \\
\hline & & \multicolumn{3}{|c|}{4} & \multicolumn{3}{|c|}{6} & \multicolumn{3}{|c|}{8} & \multicolumn{3}{|c|}{10} & \multicolumn{3}{|c|}{12} & \multicolumn{3}{|c|}{14} \\
\hline & & $\begin{array}{l}\mathrm{AE} \\
(\%)\end{array}$ & $\begin{array}{c}\mathrm{SE} \\
(\%)\end{array}$ & $\underset{(\mathrm{m})}{\mathrm{C}}$ & $\begin{array}{l}\mathrm{AE} \\
(\%)\end{array}$ & $\begin{array}{l}\text { SE } \\
(\%)\end{array}$ & $\underset{(\mathrm{m})}{\mathrm{C}}$ & $\begin{array}{l}\mathrm{AE} \\
(\%)\end{array}$ & $\begin{array}{c}\text { SE } \\
(\%)\end{array}$ & $\underset{(\mathrm{m})}{\mathrm{C}}$ & $\begin{array}{l}\mathrm{AE} \\
(\%)\end{array}$ & $\begin{array}{c}\mathrm{SE} \\
(\%)\end{array}$ & $\underset{(\mathrm{m})}{\mathrm{C}}$ & $\begin{array}{l}\mathrm{AE} \\
(\%)\end{array}$ & $\begin{array}{l}\text { SE } \\
(\%)\end{array}$ & $\underset{(\mathrm{m})}{\mathrm{C}}$ & $\begin{array}{l}\mathrm{AE} \\
(\%)\end{array}$ & $\begin{array}{l}\text { SE } \\
(\%)\end{array}$ & $\underset{(\mathrm{m})}{\mathrm{C}}$ \\
\hline 1 & 5 & 11.4 & +10.1 & 4.7 & 10.6 & -2.6 & 6.0 & 9.9 & -7.0 & 5.3 & 13.4 & -12.2 & 4.8 & 14.8 & -14.8 & 4.1 & 19.7 & -15.5 & 4.0 \\
\hline 2 & $\begin{array}{l}3 \\
7 \\
\end{array}$ & $\begin{array}{l}13.5 \\
15.7 \\
\end{array}$ & $\begin{array}{l}+8.5 \\
-5.6 \\
\end{array}$ & $\begin{array}{l}3.0 \\
6.6 \\
\end{array}$ & $\begin{array}{l}10.4 \\
14.2 \\
\end{array}$ & $\begin{array}{l}-1.3 \\
+3.7 \\
\end{array}$ & $\begin{array}{l}2.5 \\
2.0 \\
\end{array}$ & $\begin{array}{l}10.9 \\
13.3 \\
\end{array}$ & $\begin{array}{l}+0.7 \\
+5.2 \\
\end{array}$ & $\begin{array}{l}3.8 \\
7.3 \\
\end{array}$ & $\begin{array}{l}10.9 \\
20.7 \\
\end{array}$ & $\begin{array}{l}+2.8 \\
-2.0 \\
\end{array}$ & $\begin{array}{l}2.5 \\
5.5 \\
\end{array}$ & $\begin{array}{l}15.3 \\
15.7 \\
\end{array}$ & $\begin{array}{l}+4.7 \\
-7.7 \\
\end{array}$ & $\begin{array}{l}2.6 \\
4.4 \\
\end{array}$ & $\begin{array}{l}18.3 \\
12.7 \\
\end{array}$ & $\begin{array}{l}+7.4 \\
-9.5 \\
\end{array}$ & $\begin{array}{l}2.5 \\
6.0 \\
\end{array}$ \\
\hline 3 & $\begin{array}{c}1 \\
11 \\
\end{array}$ & $\begin{array}{l}20.0 \\
11.3 \\
\end{array}$ & $\begin{array}{l}+11.2 \\
+7.1 \\
\end{array}$ & $\begin{array}{c}1.2 \\
12.3 \\
\end{array}$ & $\begin{array}{c}16.4 \\
8.5 \\
\end{array}$ & $\begin{array}{l}-0.4 \\
+2.4 \\
\end{array}$ & $\begin{array}{c}1.2 \\
10.8 \\
\end{array}$ & $\begin{array}{l}23.2 \\
10.1 \\
\end{array}$ & $\begin{array}{l}+8.0 \\
-5.1 \\
\end{array}$ & $\begin{array}{l}1.0 \\
8.9 \\
\end{array}$ & $\begin{array}{c}23.2 \\
8.6 \\
\end{array}$ & $\begin{array}{l}+7.2 \\
-4.4 \\
\end{array}$ & $\begin{array}{c}0.7 \\
10.2 \\
\end{array}$ & $\begin{array}{l}22.0 \\
16.5 \\
\end{array}$ & $\begin{array}{l}-1.2 \\
-14.2 \\
\end{array}$ & $\begin{array}{l}1.6 \\
8.8 \\
\end{array}$ & $\begin{array}{l}26.8 \\
19.4 \\
\end{array}$ & $\begin{array}{l}+8.4 \\
-19.0 \\
\end{array}$ & $\begin{array}{l}1.5 \\
9.6 \\
\end{array}$ \\
\hline 4 & $\begin{array}{c}1 \\
3 \\
7 \\
11\end{array}$ & $\begin{array}{l}12.0 \\
18.5 \\
21.8 \\
26.7\end{array}$ & $\begin{array}{l}-7.2 \\
+5.2 \\
-15.1 \\
-18.4\end{array}$ & $\begin{array}{l}1.0 \\
2.7 \\
6.8 \\
7.0\end{array}$ & $\begin{array}{c}9.6 \\
15.2 \\
22.3 \\
13.1\end{array}$ & $\begin{array}{l}-3.2 \\
+8.5 \\
-11.2 \\
-5.9\end{array}$ & $\begin{array}{l}0.8 \\
2.2 \\
5.6 \\
6.0\end{array}$ & $\begin{array}{l}23.2 \\
20.5 \\
22.0 \\
13.7\end{array}$ & $\begin{array}{l}+7.2 \\
+8.3 \\
-6.9 \\
-9.5\end{array}$ & $\begin{array}{l}0.8 \\
5.0 \\
6.0 \\
6.0\end{array}$ & $\begin{array}{l}26.4 \\
34.0 \\
27.4 \\
12.1\end{array}$ & $\begin{array}{l}+5.6 \\
+24.7 \\
+3.7 \\
-10.7\end{array}$ & $\begin{array}{l}0.8 \\
4.5 \\
8.4 \\
7.0\end{array}$ & $\begin{array}{l}43.6 \\
48.3 \\
26.9 \\
17.0\end{array}$ & $\begin{array}{l}+22.8 \\
+28.3 \\
+19.0 \\
-17.0\end{array}$ & $\begin{array}{l}0.8 \\
6.0 \\
5.5 \\
8.0\end{array}$ & $\begin{array}{l}15.2 \\
48.4 \\
28.3 \\
14.8\end{array}$ & $\begin{array}{l}-10.4 \\
+29.2 \\
+25.6 \\
-12.4\end{array}$ & $\begin{array}{l}0.8 \\
7.0 \\
6.8 \\
5.8\end{array}$ \\
\hline
\end{tabular}

During the control session with changed swimming direction, the seal performed all 30 trials within the preset TR2 and some even within the TR1. Consequently, when analyzing the first trials, no significant difference between the performance of the seal in the testing phase and the first trial of the control session was found (Table 2).

The analysis of the swimming speed revealed that the seal was swimming with an average speed of $0.99 \pm 0.03 \mathrm{~m} / \mathrm{s}(n=149)$ in the RI. When the seal swam at a different swimming speed, its performance decreased significantly (Kruskal-Wallis test; $p<0.001$ ). 


\subsubsection{Stage 2}

The acquisition phase of this stage took 1898 trials (Table 1). In the first 591 trials, we presented three distances to the animal. However, the seal showed no improvement for the reproduction of the $12 \mathrm{~m}$ distance and either stopped at approximately $3 \mathrm{~m}$ from close SPs or at approximately $7 \mathrm{~m}$ from far SPs. We thus decided to dismiss the $12 \mathrm{~m}$ distance and continued with the $3 \mathrm{~m}$ and the $7 \mathrm{~m}$ distance, with which the seal reached the learning criterion after 1307 trials.

In the testing phase, the seal reproduced the $3 \mathrm{~m}$ and $7 \mathrm{~m}$ distance with an overall absolute error of $13.2 \%$ regarding the $3 \mathrm{~m}$ distance and with an absolute error of $15.4 \%$ regarding the $7 \mathrm{~m}$ distance and an overall signed error of $-2.7 \%$ and $+3.8 \%$, respectively (Table 2). Thus, the short distance was undershot; the longer distance was overshot (MannWhitney $\mathrm{U}$ test; $p<0.05)$. We did not find any correlation between the position of the SP and accuracy for any of the distances during the reproduction. This provides evidence that the reproduction was not influenced by the absolute position of the SDI and RI in space (Kruskal-Wallis test; $p>0.001$ ). In line, changing the swimming direction during the control session had no pronounced effect on the performance of the animal, as most trials were performed inside the TRs, except for three distance/SP combinations: $3 \mathrm{~m}$ distance $/ 8$ $\mathrm{m}-\mathrm{SP}, 3 \mathrm{~m}$ distance $/ 2 \mathrm{~m}-\mathrm{SP}$, and $7 \mathrm{~m}$ distance $/ 12 \mathrm{~m}-\mathrm{SP}$ (Table 2).

The swimming speeds with which the animal swam during the RI were $0.56 \pm 0.10 \mathrm{~m} / \mathrm{s}$ ( $\mathrm{n}=162 ; 3 \mathrm{~m}$ distance) and $0.90 \pm 0.20 \mathrm{~m} / \mathrm{s}(\mathrm{n}=160 ; 7 \mathrm{~m}$ distance). As in the previous stage, a lower or higher swimming speed significantly decreased the accuracy (Kruskal-Wallis test; $p<0.001)$.

\subsubsection{Stage 3}

In stage 3 of experiment 1 , the seal learned to reproduce the $1 \mathrm{~m}$ and $11 \mathrm{~m}$ distances within only 643 trials (Table 1). During data collection, the seal's reproduction accuracy for the $1 \mathrm{~m}$ and the $11 \mathrm{~m}$ distances was characterized by an absolute error of $21.9 \%$ and $12.4 \%$ and a signed error of $+5.5 \%$ and $-5.5 \%$. In this stage, similar to the previous stages of experiment 1 , a highly significant effect of the distance swum on the performance of the animal was found, as the distance of $11 \mathrm{~m}$ was reproduced with significantly higher precision than the distance of $1 \mathrm{~m}$ (Mann-Whitney $\mathrm{U}$ test; $p<0.001$ ). The position of the $\mathrm{SP}$ affected the performance of the animal for the $11 \mathrm{~m}$ distance; when the seal had to reproduce the $11 \mathrm{~m}$ distance from an SP close to the hoop station, it often underestimated the distance (Kruskal-Wallis test; $p<0.001$ ). Such a trend was not found for the $1 \mathrm{~m}$ distance (Kruskal-Wallis test; $p>0.001$ ).

The results of the control session indicate that reversing the swimming direction had no significant effect on the performance of the animal (Table 2). Only 3 out of 12 first trials in opposite swimming directions were outside the TRs, one being only slightly, $10 \mathrm{~cm}$, out of the TR2, and two overshooting the TR2 by $60 \mathrm{~cm}$ and $50 \mathrm{~cm}$ (Table 2). These three trials occurred when the seal reproduced the $1 \mathrm{~m}$ distance.

Swimming speed was determined as $0.52 \pm 0.18 \mathrm{~m} / \mathrm{s}(\mathrm{n}=159)$ for the $1 \mathrm{~m}$ distance and $0.90 \pm 0.13 \mathrm{~m} / \mathrm{s}(\mathrm{n}=159)$ for the $11 \mathrm{~m}$ distance. As in the previous stages, an alteration of the speed caused accuracy to decrease significantly regarding the $11 \mathrm{~m}$ distance (KruskalWallis test; $p<0.05$ ), but not regarding the $1 \mathrm{~m}$ distance (Kruskal-Wallis test; $p>0.001$ ).

\subsubsection{Stage 4}

In stage 4 of experiment 1 , the acquisition phase lasted 1646 trials (Table 1 ).

During the testing phase, the overall absolute errors for the $1 \mathrm{~m}, 3 \mathrm{~m}, 7 \mathrm{~m}$, and $11 \mathrm{~m}$ distances were $21.7 \%, 30.8 \%, 24.8 \%$, and $16.2 \%$, respectively. The overall signed error for the $1 \mathrm{~m}, 3 \mathrm{~m}, 7 \mathrm{~m}$, and $11 \mathrm{~m}$ distances were $+2.5 \%,+17.4 \%,+2.5 \%$ and $-12.3 \%$ (Table 2). These signed errors manifested in a significant influence of the distance on the performance of the animal, as it overshot all distances, except for the $11 \mathrm{~m}$ distance (Kruskal-Wallis test; $p<0.001)$. We also found a significant influence of the SP on the precision of the reproduction for the $3 \mathrm{~m}$ and $7 \mathrm{~m}$ distance (Kruskal-Wallis test; $p<0.05$ ). When reproducing 
these distances from an SP close to the hoop station, the seal's precision was higher than when the animal had to reproduce the distances from SPs beyond $8 \mathrm{~m}$.

Focusing on the performance of the seal during the control session, the first trial analysis for stage 4 showed that in 14 out of 24 trials, the seal reproduced the respective distances within the TRs (Table 2). In contrast to the previous stages of experiment 1 , we found a significant effect of the swimming speed on the performance of the animals solely for the $11 \mathrm{~m}$ distance (Kruskal-Wallis test; $p<0.001$; swimming speeds: $0.59 \pm 0.18 \mathrm{~m} / \mathrm{s}$ ( $\mathrm{n}=153 ; 1 \mathrm{~m}$ distance), $0.80 \pm 0.20 \mathrm{~m} / \mathrm{s}(\mathrm{n}=153 ; 3 \mathrm{~m}$ distance), $0.94 \pm 0.20 \mathrm{~m} / \mathrm{s}(\mathrm{n}=152$; $7 \mathrm{~m}$ distance), $0.99 \pm 0.18 \mathrm{~m} / \mathrm{s}(\mathrm{n}=150 ; 11 \mathrm{~m}$ distance $)$ ).

In stage 4 of experiment 1 , we also investigated the motion patterns of the animal during reproduction. We found that every distance was reproduced almost exclusively with one specific motion pattern. Regarding three distances, we found that a deviation from the specific motion pattern resulted in a significant decrease in accuracy during the reproduction; the animal favored to use the "touch-stop"-motion pattern for a distance of $1 \mathrm{~m} \mathrm{(94 \% ;} \mathrm{Chi}{ }^{2}$ test, $\left.p<0.05 ; n=147\right)$, the "touch-drift" movement pattern was associated with the reproduction of the $3 \mathrm{~m}$ distance $\left(85 \%\right.$; $\mathrm{Chi}^{2}$ test, $\left.p<0.05 ; n=149\right)$, and the "touch- dive-drift"-movement pattern occurred mainly during the reproduction of the $11 \mathrm{~m}$ distance $\left(82 \%\right.$; $\mathrm{Chi}^{2}$ test, $\left.p<0.05 ; n=148\right)$. For the $7 \mathrm{~m}$ distance, we did not find a single specific motion pattern. Here, the animal used the "touch-drift" $(44 \%)$ or the "touchdive- drift" (42\%) motion pattern but did not show a statistically significant preference between the two $\left(\mathrm{Chi}^{2}\right.$ test, $\left.p>0.05 ; n=145\right)$.

\subsubsection{Stage 5}

In stage 5 of experiment 1 , the seal had to reproduce 29 unknown combinations of distances and SPs (Figure 2). The overall absolute error was 39.2\%, and the overall signed error $+0.6 \%$. In total, 9 out of 29 trials were inside the given TR2 of $\pm 20 \%$. The medium absolute error for the first eight trials was approximately $65 \%$, whereas the trials thereafter were performed with a medium absolute error of around 30\%. Distances longer than $9.5 \mathrm{~m}$ were reproduced with higher accuracy (medium absolute error: $27.1 \%$ ) as distances shorter than $9.5 \mathrm{~m}$, which were reproduced with a medium absolute error of $54.1 \%$ (Mann-Whitney $\mathrm{U}$ test; $p<0.05)$. Moreover, the seal significantly undershot distances shorter than $9.5 \mathrm{~m}$ and overshot distances longer than $9.5 \mathrm{~m}$ (Mann-Whitney $\mathrm{U}$ test; $p<0.05$ ).

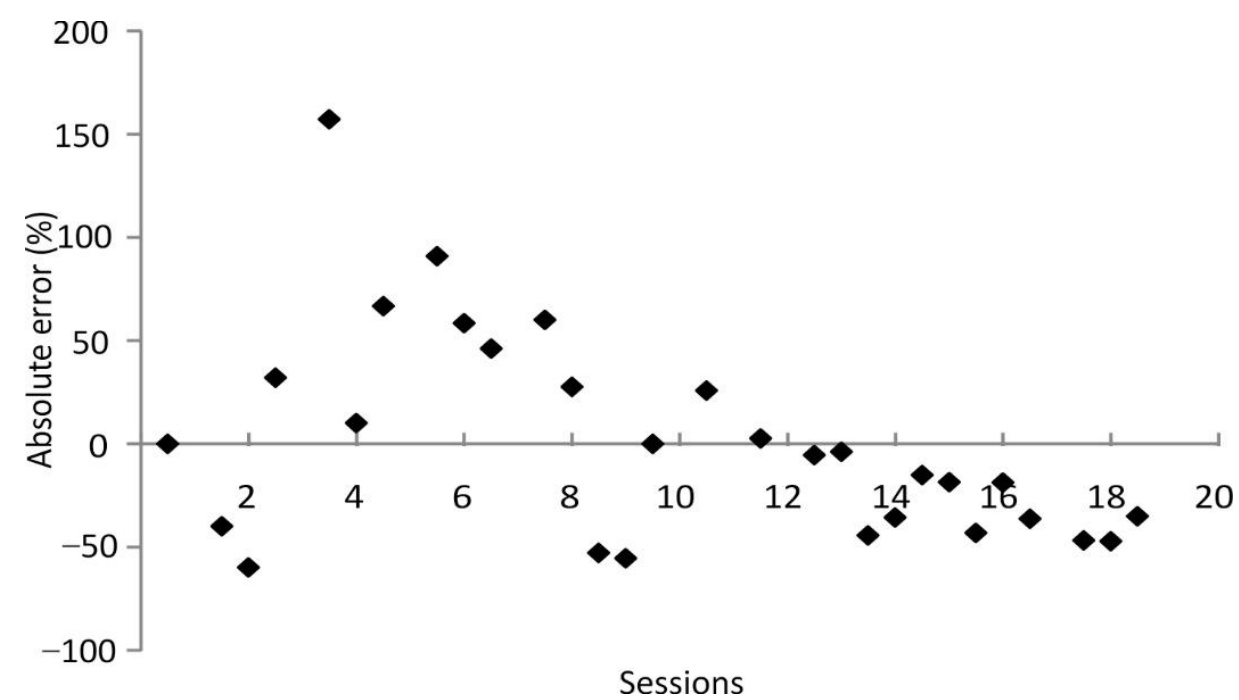

Figure 2. Signed error (in\%) for the reproduction of each unknown distance in stage 5 of experiment 1. Each combination of distance and SP was tested only once (see Appendix A). Negative values of the signed error describe an undershooting of the distance; positive values describe an overshooting. 
The position of the SP had a significant influence on the performance of the animal; the precision of the animal was higher with SPs up to $8 \mathrm{~m}$ from the hoop station and lower for SPs beyond $8 \mathrm{~m}$ (Mann-Whitney $\mathrm{U}$ test; $p<0.05)$.

\subsection{Experiment 2}

In experiment 2, it took the seal 251 trials to reach the learning criterion with a TR of $\pm 20 \%$ for the $9 \mathrm{~m}$ distance (Figure $3 \mathrm{~A}$ ). In the course of training, the seal managed to reach the learning criterion for two subsequently defined TRs, $\pm 17.5 \%$ and $\pm 15 \%$. The average absolute error for the last ten sessions was $12.7 \%$. However, during testing, the minimal absolute error during a session was determined as $6.4 \%$.

When training with the $2 \mathrm{~m}$ distance, the seal needed 312 trials to reach the learning criterion with a TR of $\pm 20 \%$ (Figure $3 \mathrm{~B}$ ). Thereafter, it met the learning criterion for a TR of $\pm 15 \%$ as well. In the end, the seal did not reach the learning criterion for a TR of $\pm 10 \%$. The average absolute error for the last 10 sessions was $16.4 \%$, while the absolute minimum error achieved during a session was $9.8 \%$.

During training with a $13 \mathrm{~m}$ distance, the trial number to reach the first learning criterion with a TR of $\pm 20 \%$ decreased to 120 trials (Figure $3 \mathrm{C}$ ). Additionally, the seal reached the learning criterion for the two subsequent TRs of $\pm 15 \%$ and $\pm 10 \%$ as well, before failing to reach the learning criterion for a TR of $\pm 5 \%$. In the last five sessions, the seal showed an overall absolute error of $9.8 \%$. The minimum absolute error per session was $6.7 \%$.

\subsection{Experiment 3}

In experiment 3, the seal was asked to perform the distance reproduction task with (masked trials) and without visual masking (baseline trials). The learning criterion for the baseline trials was reached after 140 trials. In the testing phase, the seal reproduced the distance during unmasked trials with an average absolute error of $17.2 \%$ and during masked trials with an average absolute error of $21.1 \%$. The seal's performance during masked trials was significantly worse than in the baseline trials (Mann-Whitney U test; $p=0.037)$. 

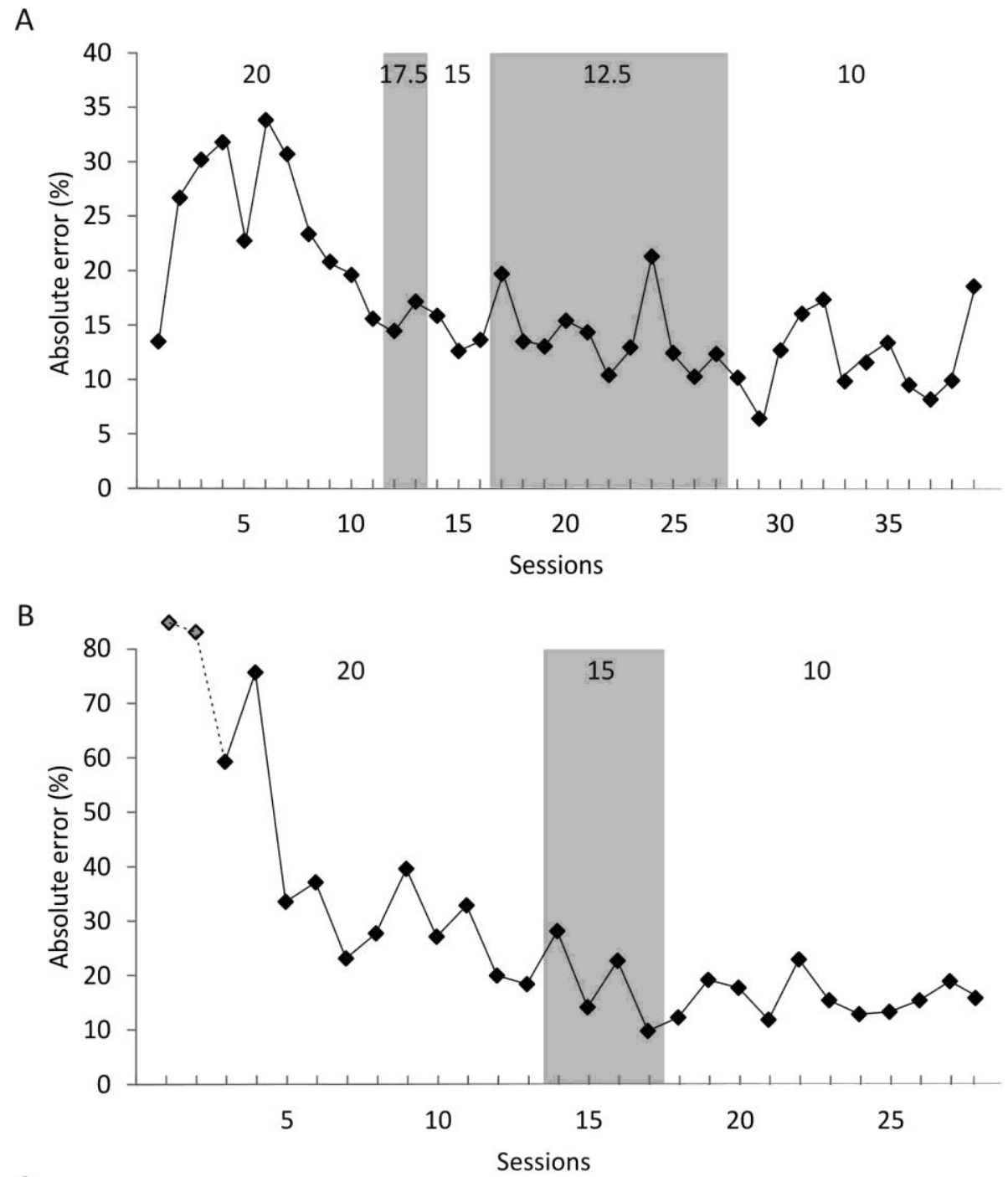

C

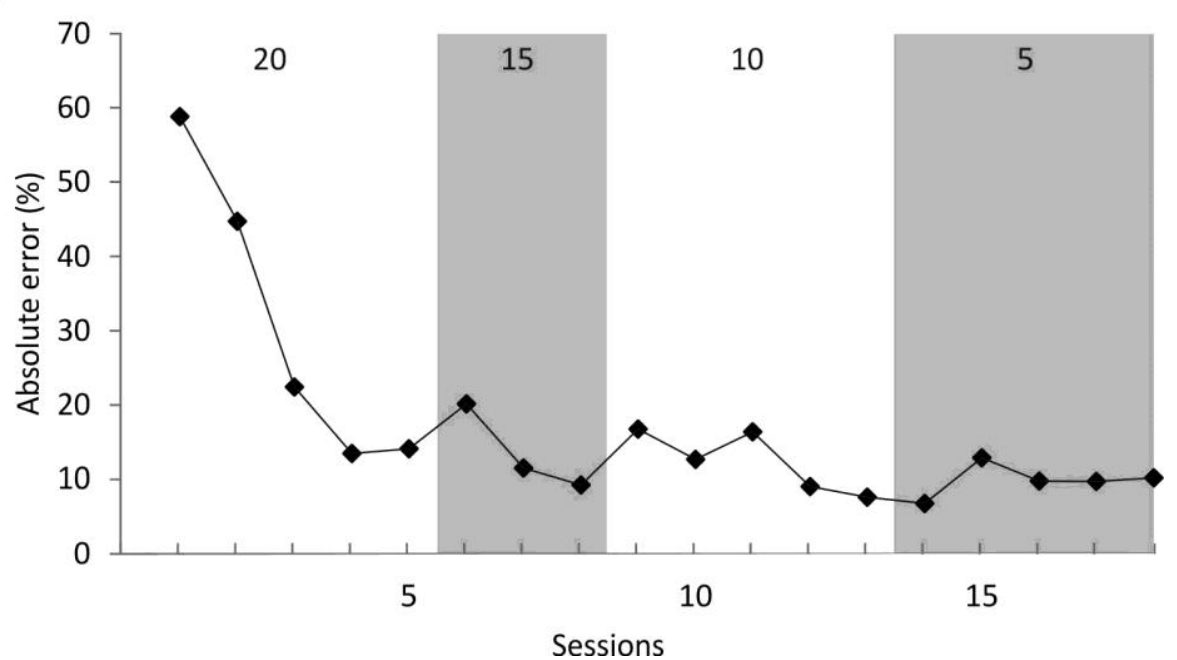

Figure 3. Results of experiment 2. Average absolute error for each session conducted: (A) $9 \mathrm{~m}$ distance; (B) $2 \mathrm{~m}$ distance; (C) $13 \mathrm{~m}$ distance. Every data-point depicts the average absolute error during one session with pseudorandomized SPs. Experimental blocks comprise the performance for the different TR, the seal experienced during the sessions. Due to portrayal issues, we did not illustrate the right scale of the axis for graph B and excluded the to-scale portrayal of the first two values. These values were $360 \%$ and $277 \%$. 


\section{Discussion}

In this study, we analyzed the distance estimation ability of one captive harbor seal, which was available for the extended behavioral experiments. Consequently, the conclusions drawn always need to be considered taking this small sample size as well as the laboratory conditions of our large seawater enclosure, under which the data were obtained, into account and will remain speculative regarding the behavior of wild seals. However, the experimental animal behaves normally and does not have any general deficits, which makes us confident about the reliability of the data concerning this seal individual.

In experiment 1 , in phases $1-4$, we could show that a harbor seal can learn to estimate and reproduce distances between 1 and $13 \mathrm{~m}$ within a predefined range of accuracy. This conclusion is based on the fact that, when presented with two or more distances within one session, the seal could only solve the task if it had derived distance information from the SDI. The use of memorized EPs to solve the task can largely be excluded, as (1) we asked the seal to perform from numerous SPs, (2) the seal was able to perform successfully in most first trials when asked to run the experiment with inversed swimming direction in the control sessions, and (3), over the course of the experiment, one point in space could have been the EP of two SP/SDI combinations, such as $12 \mathrm{~m} / 3 \mathrm{~m}$ and $14 \mathrm{~m} / 1 \mathrm{~m}$. Thus, we present the first evidence for distance estimation and reproduction in a marine mammal, the harbor seal. Previously, distance estimation has only been demonstrated in terrestrial animals, such as in insects, gerbils, and humans (see, for example, [18,45-48]). However, as aquatic mammals, harbor seals may also profit from this ability when navigating their environment using, for example, path integration or path return (see Introduction) to find their way back to a location, such as a haul-out place.

In the first stages of experiment 1 , the question was addressed, if a harbor seal could learn to reproduce distances in a reproduction task typically used with human subjects. The seal here showed an absolute error between $12 \%$ and $31 \%$. This means that not only can the seal learn to reproduce single and multiple distances, but the resulting precision from the experiment also implies that seals could use distance estimation for navigation purposes. Short distances, when seals stay close to shore, could thus be estimated effectively. However, even on a journey covering kilometers, the precision shown in the first phases of experiment 1 would bring the animal close enough towards its goal to then to pinpoint the exact location using, for example, visual cues; for visual cues to be effectively used to, for example, spot a haul-out place rising only $0.1 \mathrm{~m}$ above the water surface under good visibility at sea $[49,50]$, the seal would need to get as close as $1.2 \mathrm{~km}$. Additionally, information obtained by other sensory systems can reduce the errors that might accumulate when large distances are traveled or during path integration.

Two interesting phenomena were documented that provide evidence regarding the mechanism of distance estimation in our reproduction tasks. First, the seal used motoric cues to reproduce a distance. All distances, except for one distance, were reproduced with a specific motion pattern, and the accuracy of reproduction was highest if the seal used a specific motion pattern for the reproduction of a specific distance. We consider it unlikely that seals are using specific motion patterns for every single distance traveled in the wild. However, seals might nevertheless use motoric cues to reproduce and maybe to estimate distances in general. Harbor seals could, for example, apply a pedometer comparable to desert ants $[37,51]$. In seals, this would correspond to counting the number of tail fin flaps, which might be revealed when seals are asked to estimate larger distances. A detailed analysis of GPS recordings in combination with accelerometer tags [52,53] might even enable researchers to determine whether the number of tail fin flaps correlates with the distance swum in wild seals. Second, the seal's performance was highest if it was reproducing a distance with a specific swimming speed. As previously it was documented that harbor seals have an accurate sense of time [54,55], the seal might have kept swimming speed constant, allowing it to use time as a measure for distance. Future studies are required to further elucidate the mechanism of distance estimation in harbor seals. These studies also need to consider ecological factors, such as waves or ocean currents, determining 
whether seals can perceive and compensate for them or whether these present challenges for using motoric cues or for the determination of swimming speed.

In phase 5 of experiment 1 , we asked the seal to reproduce new distances without prior acquisition/learning phase for these distances. The seal's precision noticeably dropped in this stage to an overall error of $39.2 \%$. However, its accuracy was best, with a mean absolute error of $27.1 \%$, when asked to reproduce distances $\geq 10 \mathrm{~m}$, which is comparable to the previous stages that included acquisition phases. On the one hand, the seal might have performed better for distances $\geq 10 \mathrm{~m}$ as these are most likely of higher ecological relevance. Seals in their natural habitat are reported to travel distances of dozens of kilometers per day [56]. However, a fine-scale analysis of these trips needs to be done to unravel if these long trips consist of short-distance legs in which distances in the range of the distances or slightly beyond those presented in this study are covered. On the other hand, the seal might have performed worse for distances $<10 \mathrm{~m}$ as it had already gained extensive experience for distances in this short-range in stages $1-4$ of experiment 1 . Its previous experience might have negatively affected his performance for distances $<10 \mathrm{~m}$ in the final phase as it might have tried to fit a solution, such as a motion pattern, for a previously presented distance to a new distance of comparable length. In conclusion, comparing the results of phases 1-4 to the results of phase 5 of experiment 1 , repeatedly swimming a specific path/distance increases accuracy, but nevertheless, even when asked to reproduce unknown distances, the seal achieved accuracy in the same range when presented with distances longer than $10 \mathrm{~m}$.

The maximum precision a seal can reach during the reproduction of a repeatedly swum distance was assessed in experiment 2 . We found that with specific training to the highest possible precision, the harbor seal's absolute error for distance reproduction could decrease to a precision lower than $10 \%$. The highest accuracy, an absolute error as small as $6.4 \%$, was documented for the $9 \mathrm{~m}$ distance. We can thus further stress that the seal's precision when repeatedly swimming a specific distance can be very high. Tagging wild seals has indeed revealed that some seals occasionally choose a specific route repeatedly [57]. Consequently, under these circumstances, they will be able to precisely locate their goal.

The final experiment 3 revealed that the occlusion of vision does not have a major effect on distance reproduction. Instead, (1) the seal quickly transferred the paradigm to the non-visual procedure, (2) even when blindfolded, the distance was reproduced with an error comparable to the errors documented in studies involving human subjects in similar tasks $[27,45]$, and (3) the difference in accuracy when reproducing a distance without a blindfold and with the blindfold was, although significantly different, only $4 \%$. These results most likely mimic that seals frequently encounter conditions in which vision is reduced, such as when active at night or when diving in dark or turbid waters. Future experiments can address the role of other senses during distance estimation. Moreover, in line with our original thought, it would be interesting to examine the seal's ability to estimate and reproduce distances solely based on idiothetic cues and then to put it into the larger context of path integration and orientation/navigation in general.

Throughout the experiment, the seal did not show the same motion pattern in the SDI and the RI; whereas it swam parallel to the belt in the SDI, it included curves or diving phases into the RI. The distance swam during the RI thus deviated from the distance of the SDI. However, the horizontal distance of both intervals matched. Documentation of the horizontal distance to compute a homing vector has been shown for the desert ant, if the ant was foraging in uneven terrain $[38,58]$. It may be highly adaptive for a harbor seal to also neglect the third dimension, meaning to not include the diving profile into the estimation of traveled distance as its diving pattern and thus distance traveled most likely deviate between the out- and inbound trip. Instead, it would be advantageous to keep track of the horizontal distance, which the seal did during our experiment.

In our study, we also found an influence of the distance on the precision of the animal. The seal was, in general, overshooting short distances and undershooting the reproduction of long distances as previously reported, for example, in humans [59]. The underestimation 
of long distances has been explained by the amount of information intake exceeding the processing capabilities of the brain [59]. This overflow of information results in a less accurate estimation of the distance; the animal is coming short [60]. An underestimation of a distance can be highly adaptive and has been observed, for example, during path integration [21]. If the animal underestimates the distance of its homing vector, it is not directly brought back to its goal, but its homing vector ends close to its goal. In the familiar terrain close to the goal, the animal can then use, for example, landmarks or the panorama to locate its goal precisely [61]. An interesting future experiment, besides experiments on path integration or path return, could be a visual distance estimation experiment [30], in which the seal must approach a goal, at which a target was presented, before the animal starts to move towards it. Such an experiment would mimic a natural situation, in which the seal was viewing a landmark at the water surface and was approaching it underwater without directly seeing the landmark anymore. These experiments could then be complemented by studies on the use of landmarks.

\section{Conclusions}

For the first time, we were able to show that a marine mammal can learn to use distance information in reproduction tasks. The captive, experimentally experienced seal could also estimate and reproduce distances largely independent from environmental cues under laboratory conditions. Additionally, we could show that the seal's precision can be compared to that of human subjects, and visual input may not be imminent for distance reproduction. The precision achieved during distance estimation/reproduction would enable the seal to use navigational strategies, such as path integration or path return, especially when covering short absolute distances to prevent the accumulation of errors, but also when traveling larger distances and/or when the information provided by the sensory systems is considered, which are possible strategies used by seals in their challenging habitat.

Author Contributions: Conceptualization, E.M. and F.D.H.; methodology, E.M. and F.D.H.; formal analysis, E.M.; investigation, E.M.; writing —original draft preparation, E.M.; writing-review and editing, E.M. and F.D.H.; visualization, E.M.; supervision, F.D.H.; project administration, E.M.; funding acquisition, E.M. and F.D.H. All authors have read and agreed to the published version of the manuscript.

Funding: The authors would like to acknowledge the financial support of the Deutsche Bundesstiftung Umwelt to EM and the VolkswagenStiftung to FDH.

Institutional Review Board Statement: The experiments were carried out in accordance with the European Communities Council Directive of 24 November 1986 (86/609/EEC). According to $\$ 8$ of the German Animal Welfare Act of 18 May 2006 (BGB I. I S. 1206, 1313), experiments conducted in this study were not subject to approval or notification since they did not cause pain, suffering or injuries to the animals.

Data Availability Statement: All data are available in this manuscript. Detailled raw data are available from the authors on request.

Acknowledgments: We would like to thank all the members of the Marine Science Center for their encouragement and support during the conceptualization and experimental phases of the project. Special thanks go to all the numerous interns who participated as observers during the times of the experiment.

Conflicts of Interest: The authors declare no conflict of interest. 


\section{Appendix A}

Table A1. Overview of the SPs (in $\mathrm{m}$ from hoop station) and the distances (in $\mathrm{m}$ ) presented from the SPs tested in stage 5 of experiment 1 . All combinations were presented in pseudorandomized order and are only depicted by order of increasing distance for a better overview here.

\begin{tabular}{cc}
\hline SP (m from Hoop Station) & $\begin{array}{c}\text { Distance } \\
(\mathbf{m})\end{array}$ \\
\hline 11 & 0.5 \\
10.5 & 1.5 \\
12 & 2 \\
11.5 & 2.5 \\
14.5 & 3.5 \\
13 & 4 \\
12.5 & 4.5 \\
10 & 5.5 \\
9.5 & 6 \\
13.5 & 6.5 \\
8 & 7.5 \\
14 & 8 \\
4.5 & 8.5 \\
3.5 & 9 \\
15 & 9.5 \\
9 & 10.5 \\
7.5 & 11.5 \\
8.5 & 12.5 \\
7 & 13 \\
5 & 13.5 \\
6.5 & 14 \\
4 & 14.5 \\
5.5 & 15 \\
2.5 & 15.5 \\
3 & 16 \\
2 & 16.5 \\
1.5 & 17.5 \\
1 & 18 \\
0.5 & 18.5 \\
\hline &
\end{tabular}

\section{References}

1. Horton, T.W.; Holdaway, R.N.; Zerbini, A.N.; Hauser, N.; Garrigue, C.; Andriolo, A.; Clapham, P.J. Straight as an arrow: Humpback whales swim constant course tracks during long-distance migration. Biol. Lett. 2011, 7, 674-679. [CrossRef] [PubMed]

2. Mate, B.R.; Lagerquist, B.A.; Calambokidis, J. Movements of north pacific blue whales during the feeding season off southern california and their southern fall migration. Mar. Mammal Sci. 1999, 15, 1246-1257. [CrossRef]

3. Oliver, G.W.; Morris, P.A.; Thorson, P.H.; Boeuf, B.J. Homing behavior of juvenile northern elephant seals. Mar. Mammal Sci. 1998, 14, 245-256. [CrossRef]

4. Russell, D.J.; Brasseur, S.M.; Thompson, D.; Hastie, G.D.; Janik, V.M.; Aarts, G.; McClintock, B.T.; Matthiopoulos, J.; Moss, S.E.; McConnell, B. Marine mammals trace anthropogenic structures at sea. Curr. Biol. 2014, 24, R638-R639. [CrossRef] [PubMed]

5. Matsumura, M.; Watanabe, Y.Y.; Robinson, P.W.; Miller, P.J.O.; Costa, D.P.; Miyazaki, N. Underwater and surface behavior of homing juvenile northern elephant seals. J. Exp. Biol. 2011, 214, 629-636. [CrossRef]

6. Nyqvist, D.; Durif, C.; Johnsen, M.G.; De Jong, K.; Forland, T.N.; Sivle, L.D. Electric and magnetic senses in marine animals, and potential behavioral effects of electromagnetic surveys. Mar. Environ. Res. 2020, 155, 104888. [CrossRef]

7. Nordmann, G.C.; Hochstoeger, T.; Keays, D.A. Magnetoreception-A sense without a receptor. PLoS Biol. 2017, 15, e2003234. [CrossRef]

8. Putman, N.F.; Lohmann, K.J. Compatibility of magnetic imprinting and secular variation. Curr. Biol. 2008, 18, R596-R597. [CrossRef]

9. Mauck, B.; Brown, D.; Schlosser, W.; Schaeffel, F.; Dehnhardt, G. How a harbour seal sees the night sky. Mar. Mammal Sci. 2005, 21, 646-656. [CrossRef]

10. Mauck, B.; Gläser, N.; Schlosser, W.; Dehnhardt, G. Harbour seals (Phoca vitulina) can steer by the stars. Anim. Cogn. 2008, 11, 715-718. [CrossRef] [PubMed] 
11. Renouf, D. Sensory reception and processing in Phocidae and Otariidae. In The Behaviour of Pinnipeds; Metzler, J.B., Ed.; Springer: Dordrecht, The Netherlands, 1991; pp. 345-394.

12. Kowalewsky, S.; Dambach, M.; Mauck, B.; Dehnhardt, G. High olfactory sensitivity for dimethyl sulphide in harbour seals. Biol. Lett. 2005, 2, 106-109. [CrossRef] [PubMed]

13. Hanke, W.; Wieskotten, S.; Marshall, C.; Dehnhardt, G. Hydrodynamic perception in true seals (Phocidae) and eared seals (Otariidae). J. Comp. Physiol. A 2012, 199, 421-440. [CrossRef]

14. Hanke, W.; Dehnhardt, G. Sensory biology of aquatic mammals. J. Comp. Physiol. A 2013, 199, 417-420. [CrossRef]

15. Weiffen, M.; Möller, B.; Mauck, B.; Dehnhardt, G. Effect of water turbidity on the visual acuity of harbor seals (Phoca vitulina). Vis. Res. 2006, 46, 1777-1783. [CrossRef] [PubMed]

16. Mittelstaedt, M.-L.; Mittelstaedt, H. Homing by path integration in a mammal. Naturwissenschaften 1980, 67, 566-567. [CrossRef]

17. Mittelstaedt, H.; Mittelstaedt, M.-L. Homing by path integration. In Proceedings in Life Sciences; Springer: Berlin/Heidelberg, Germany, 1982; pp. 290-297.

18. Kautzky, M.; Thurley, K. Estimation of self-motion duration and distance in rodents. R. Soc. Open Sci. 2016, 3, 160118. [CrossRef]

19. Benhamou, S. Path integration by swimming rats. Anim. Behav. 1997, 54, 321-327. [CrossRef]

20. Collet, T.S.; Collet, M. Path integration in insects. Curr. Opin. Neurobiol. 2000, 10, 757-762. [CrossRef]

21. Etienne, A.S.; Jeffery, K.J. Path integration in mammals. Hippocampus 2004, 14, 180-192. [CrossRef]

22. Kimchi, T.; Etienne, A.S.; Terkel, J. A subterranean mammal uses the magnetic compass for path integration. Proc. Natl. Acad. Sci. USA 2004, 101, 1105-1109. [CrossRef]

23. Moller, P.; Görner, P. Homing by path integration in the spider Agelena labyrinthica Clerk. J. Comp. Physiol. A 1994, 174, 221-229. [CrossRef]

24. Seguinot, V.; Cattet, J.; Benhamou, S. Path integration in dogs. Anim. Behav. 1998, 55, 787-797. [CrossRef]

25. Zeil, J.; Hemmi, J.M. Path integration, vision, and decision-making in fiddler crabs. In Nervous Systems and Control of Behavior in the Natural History of the Crustacea (Volume 3); Oxford University Press: Oxford, UK, 2014; Volume 3, pp. 484-508.

26. Fuiman, L.A.; Williams, T.M.; Davis, R.W. Homing tactics of Weddell seals in the Antarctic fast-ice environment. Mar. Biol. 2020, 167, 1-16. [CrossRef]

27. Klatzky, R.L.; Loomis, J.M.; Golledge, R.G.; Cicinelli, J.G.; Doherty, S.; Pellegrino, J.W. Acquisition of route and survey knowledge in the absence of vision. J. Mot. Behav. 1990, 22, 19-43. [CrossRef]

28. Mittelstaedt, M.-L.; Mittelstaedt, H. Idiothetic navigation in humans: Estimation of path length. Exp. Brain Res. 2001, 139, 318-332. [CrossRef] [PubMed]

29. Cohen, H.S.; Sangi-Haghpeykar, H. Walking speed and vestibular disorders in a path integration task. Gait Posture 2011, 33, 211-213. [CrossRef] [PubMed]

30. Glasauer, S.; Amorim, M.-A.; Vitte, E.; Berthoz, A. Goal-directed linear locomotion in normal and labyrinthine-defective subjects. Exp. Brain Res. 1994, 98, 323-335. [CrossRef] [PubMed]

31. Esch, H.E.; Burns, J.E. Honeybees use optic flow to measure the distance of a food source. Naturwissenschaften 1995, 82, 38-40. [CrossRef]

32. Si, A.; Srinivasan, M.V.; Zhang, S. Honeybee navigation: Properties of the visually driven 'odometer'. J. Exp. Biol. 2003, 206, 1265-1273. [CrossRef]

33. Srinivasan, M.V. Going with the flow: A brief history of the study of the honeybee's navigational 'odometer'. J. Comp. Physiol. A Neuroethol. Sens. Neural Behav. Physiol. 2014, 200, 563-573. [CrossRef]

34. Srinivasan, M.V.; Zhang, S.; Altwein, M.; Tautz, J. Honeybee navigation: Nature and calibration of the "odometer". Science 2000, 287, 851-853. [CrossRef]

35. Srinivasan, M.V.; Zhang, S.W.; Bidwell, N.J. Visually medited odometry in honeybees. J. Exp. Biol. 1997, $200,2513-2522$.

36. Ronacher, B. Path integration in a three-dimensional world: The case of desert ants. J. Comp. Physiol. A 2020, 206, 379-387. [CrossRef]

37. Wittlinger, M.; Wehner, R.; Wolf, H. The desert ant odometer: A stride integrator that accounts for stride length and walking speed. J. Exp. Biol. 2007, 210, 198-207. [CrossRef]

38. Wohlgemuth, S.; Ronacher, B.; Wehner, R. Ant odometry in the third dimension. Nat. Cell Biol. 2001, 411, 795-798. [CrossRef]

39. Wehner, R. Desert Navigator: The Journey of the Ant; Harvard University Press: Cambridge, MA, USA, 2020.

40. Maurer, R.; Etienne, A.S. Dead reckoning in a small mammal: The evaluation of distance. J. Comp. Physiol. A 1993, 173, 103-113. [CrossRef]

41. Schulte-Pelkum, N.; Wieskotten, S.; Hanke, W.; Dehnhardt, G.; Mauck, B. Tracking of biogenic hydrodynamic trails in harbour seals (Phoca vitulina). J. Exp. Biol. 2007, 210, 781-787. [CrossRef] [PubMed]

42. Byl, J.A.; Miersch, L.; Wieskotten, S.; Dehnhardt, G. Underwater sound localization of pure tones in the median plane by harbor seals (Phoca vitulina). J. Acoust. Soc. Am. 2016, 140, 4490-4495. [CrossRef] [PubMed]

43. Berthoz, A.; Israel, I.; Georges-Francois, P.; Grasso, R.; Tsuzuku, T. Spatial memory of body linear displacement: What is being stored? Science 1995, 269, 95-98. [CrossRef] [PubMed]

44. Gellermann, L.W. Chance orders of alternating stimuli in visual discrimination experiments. Pedagog. Semin. J. Genet. Psychol. 1933, 42, 206-208. [CrossRef] 
45. Bigel, M.G.; Ellard, C.G. The contribution of nonvisual information to simple place navigation and distance estimation: An examination of path integration. Can. J. Exp. Psychol. Rev. Can. Psychol. Exp. 2000, 54, 172-185. [CrossRef]

46. Durier, V.; Rivault, C. Path integration in cockroach larvae, Blattella germanica (L.) (insect: Dictyoptera): Direction and distance estimation. Learn. Behav. 1999, 27, 108-118. [CrossRef]

47. Corlett, J.T.; E Patla, A.; Williams, J.G. Locomotor estimation of distance after visual scanning by children and adults. Perception 1985, 14, 257-263. [CrossRef] [PubMed]

48. Ellard, C.G.; Goodale, M.A.; Timney, B. Distance estimation in the mongolian gerbil: The role of dynamic depth cues. Behav. Brain Res. 1984, 14, 29-39. [CrossRef]

49. Pick, W.H. Visibility at sea. Q. J. R. Meteorol. Soc. 1932, 58, 251-258. [CrossRef]

50. Deutscher Wetterdienst. Available online: https://www.dwd.de/DE/service/lexikon/Functions/glossar.html?lv2=101640\&lv3 $=101756$ (accessed on 22 March 2021).

51. Wittlinger, M.; Wehner, R.; Wolf, H. The ant odometer: Stepping on stilts and stumps. Science 2006, 312, 1965-1967. [CrossRef]

52. Sato, K.; Mitani, Y.; Cameron, M.F.; Siniff, D.B.; Naito, Y. Factors affecting stroking patterns and body angle in diving Weddell seals under natural conditions. J. Exp. Biol. 2003, 206, 1461-1470. [CrossRef]

53. Watanabe, Y.; Baranov, E.A.; Sato, K.; Naito, Y.; Miyazaki, N. Body density affects stroke patterns in Baikal seals. J. Exp. Biol. 2006, 209, 3269-3280. [CrossRef] [PubMed]

54. Heinrich, T.; Dehnhardt, G.; Hanke, F.D. Harbour seals (Phoca vitulina) are able to time precisely. Anim. Cogn. 2016, 19, 1133-1142. [CrossRef] [PubMed]

55. Heinrich, T.; Ravignani, A.; Hanke, F.D. Visual timing abilities of a harbour seal (Phoca vitulina) and a South African fur seal (Arctocephalus pusillus pusillus) for sub- and supra-second time intervals. Anim. Cogn. 2020, 23, 851-859. [CrossRef] [PubMed]

56. Stewart, B.S.; Leatherwood, S.; Yochem, P.K.; Heide-Jorgensen, M.-P. Harbor seal tracking and telemetry by satellite. Mar. Mammal Sci. 1989, 5, 361-375. [CrossRef]

57. Liebsch, N.S. Hankering Back to Ancestral Pasts: Constraints on two Pinnipeds, Phoca vitulina \& Leptonychotes weddellii Foraging from a Central Place. Ph.D. Thesis, Christian, Albrechts Universität Kiel, Kiel, Germany, May 2006.

58. Wohlgemuth, S.; Ronacher, B.; Wehner, R. Distance estimation in the third dimension in desert ants. J. Comp. Physiol. A 2002, 188, 273-281. [CrossRef] [PubMed]

59. Lappe, M.; Stiels, M.; Frenz, H.; Loomis, J.M. Keeping track of the distance from home by leaky integration along veering paths. Exp. Brain Res. 2011, 212, 81-89. [CrossRef] [PubMed]

60. Lappe, M.; Jenkin, M.; Harris, L.R. Travel distance estimation from visual motion by leaky path integration. Exp. Brain Res. 2007, 180, 35-48. [CrossRef] [PubMed]

61. Wystrach, A.; Schwarz, S.; Schultheiss, P.; Beugnon, G.; Cheng, K. Views, landmarks, and routes: How do desert ants negotiate an obstacle course? J. Comp. Physiol. A 2010, 197, 167-179. [CrossRef] [PubMed] 